\title{
TIME TRENDS AND SURVIVAL AFTER OPERATIONS FOR PRIMARY LUNG CANCER FROM 1976 THROUGH 1990
}

\author{
Hiromi Wada, MD \\ Fumihiro Tanaka, MD \\ Kazuhiro Yanagihara, MD \\ Tetsuya Ariyasu, MD \\ Tatsuo Fukuse, MD \\ Hiroyasu Yokomise, MD \\ Kenji Inui, MD \\ Hiroshi Mizuno, MD \\ Osamu Ike, MD \\ Shigeki Hitomi, MD
}

\begin{abstract}
To assess the time trends and survivals after operations for primary lung cancer, the cases of 845 consecutive patients who underwent thoracotomy between 1976 and 1990 were retrospectively reviewed by groups corresponding to year of the operation (the early period was 1976 to $1980, n=208$; the middle period was 1981 to $1985, n=291$, and the late period was 1986 to $1990, n=346$ ). The 5-year survivals at the early, the middle, and the late periods were $31.5 \%, 39.0 \%$, and $54.0 \%$, respectively, with significant improvement particularly at the late period $(p<0.05$ for the early period vs the middle period, $p<0.01$ for the early or middle period vs the late period); the improvement was caused by increase in the ratio of patients with stage I disease $\mathbf{2 0 . 7 \%}$ at the early period, $32.0 \%$ at the middle period, 44.2\% at the late period), increase in the rates of complete tumor resection with lymph node dissection $(57.2 \%, 68.0 \%, 74.3 \%$, respectively), and decrease in the rates of operation-related death $(3.8 \%, 3.4 \%, 0.9 \%$, respectively). The postoperative prognosis of patients with stage $I$ disease at the late period (5-year survival $\mathbf{7 4 . 8 \%}$ ) showed significant improvement compared with the other periods. Moreover, the prognosis of patients with stage IIIa, pN2 disease (5-year survival 41.5\%) showed significant improvement, which was caused by the significant decrease in patients with pT3 N2 M0 disease and poor prognosis. (J Thorac Cardiovase Surg 1996;112:349-55)
\end{abstract}

$T^{\mathrm{h}}$ he prognosis after operation for primary lung cancer (PLC) remains poor despite recent advances both in diagnostic imaging, such as computed tomography (CT) and magnetic resonance imaging, and in adjuvant therapy. Five-year survivals have been reported to range between approximately $20 \%$ to $30 \%{ }^{1}$ Only a few reports, ${ }^{2}$ however, have been published with respect to the time trends of survival after operation for PLC. Moreover, because the present international staging system for $\mathrm{PLC}^{3}$ was revised in 1986, it is difficult to compare prognoses based on the old staging system with those based on the current staging system. ${ }^{4}$ To determine whether the survival of patients who underwent operations

From the Department of Thoracic Surgery, Chest Disease Research Institute, Kyoto University, Kyoto, Japan.

Received for publication July 21, 1995; revisions requested Sept. 13, 1995; revisions received Nov. 20, 1995; accepted for publication Jan. 3, 1996.

Address for reprints: Hiromi Wada, MD, Department of Thoracic Surgery, Chest Disease Research Institute, Kyoto University, Shogoinn-kawahara machi 53-1, Sakyo-ku, Kyoto, 606, Japan.

Copyright 101996 by Mosby-Year Book, Inc.

$0022-5223 / 96 \$ 5.00+0 \quad \mathbf{1 2 / 1 / 7 1 6 0 0}$ for PLC did improve, we examined the time trends for survival after operation for PLC during the past 15 years at a single institution.

\section{Patients and methods}

A total of 845 patients who underwent thoracotomy for PLC at the Department of Thoracic Surgery, Chest Disease Research Institute, Kyoto University, during the past 15 years (from January 1, 1976, to December 31, 1990) were retrospectively reviewed and studied. Patients were grouped according to the year when thoracotomy was performed: the early period (from 1976 to 1980), the middle period (from 1981 to 1985), and the late period (from 1986 to 1990). There were 629 male and 216 female patients. Mean age at thoracotomy was $61.5 \pm 9.8$ years (mean \pm standard deviation, range 17 to 83 years).

Investigation was performed with all inpatient medical records, chest radiographs, whole-body CT films, bone and gallium scanning data, operative records, and pathologic specimens. For patients who underwent operation in 1981 and later, whole-body CT and bone and gallium scan were routinely taken. Mediastinoscopy was not routinely employed. Histologic typing was conducted according to the classification of the World Health Organization. ${ }^{5}$ Tumor extent was evaluated according to the current TNM classification, revised in $1986 ;^{3}$ reevaluation according to the present TNM classification was performed for patients who underwent operation before 1986. Complete tumor resection was defined as no microscopic cancers 
Table I. Characteristics of patients

\begin{tabular}{|c|c|c|c|c|}
\hline & \multicolumn{3}{|c|}{ Year of operation } & \multirow[b]{2}{*}{ Time trend $P$} \\
\hline & $\begin{array}{c}1976 \text { to } 1980 \\
(n=208)\end{array}$ & $\begin{array}{c}1981 \text { to } 1985 \\
(n=291)\end{array}$ & $\begin{array}{c}1986 \text { to } 1990 \\
(n=346)\end{array}$ & \\
\hline Sex (male:female) & $160: 48$ & $213: 78$ & $256: 90$ & 0.50 \\
\hline Age (mean $\pm S D)$ & $59.7 \pm 10.3$ & $61.2 \pm 10.0$ & $63.0 \pm 9.1 * \dagger$ & \\
\hline \multicolumn{5}{|l|}{ Histologic type } \\
\hline Squamous cell & $101(48.6 \%)$ & $113(38.8 \%) \ddagger$ & $108(31.1 \%) * \S$ & $<0.01$ \\
\hline Adenocarcinoma & $69(33.2 \%)$ & $129(44.3 \%) \div$ & $175(50.4 \%)^{*}$ & $<0.01$ \\
\hline Large cell & $22(10.6 \%)$ & $18(6.2 \%)$ & $22(6.2 \%)$ & 0.11 \\
\hline Small cell & $6(2.9 \%)$ & $20(6.9 \%)$ & $22(6.2 \%)$ & 0.08 \\
\hline Others & 10 & 11 & 22 & \\
\hline
\end{tabular}

Time trend analysis by $\chi^{2}$ test. ${ }^{6}$

$" p<0.01,1976$ to 1980 vs 1986 to 1990 .

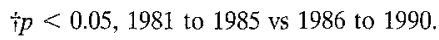

\$p $<0.05,1976$ to 1980 vs 1981 to 1985 .

$\S p<0.01,1981$ to 1985 vs 1986 to 1990 .

identified, neither in the resection margins of the tumor nor in the highest mediastinal lymph nodes. In patients who did not undergo lymph node dissection, routine sampling of various lymph node stations was performed intraoperatively to determine the pathologic staging. Follow-up of the postoperative clinical course was conducted through out-patient medical records and inquiries by telephone or letter. For patients referred to other hospitals for postoperative follow-up, medical information concerning the cause and date of death was obtained from those hospitals. Follow-up was complete and survival could be determined accurately and reliably across the three periods of the study. The day of the thoracotomy for the primary pulmonary lesion was regarded as the starting day for measuring postoperative survival.

Statistical methods. Counts were compared with the use of $\chi^{2}$ analysis; $\chi^{2}$ test for trend ${ }^{6}$ was employed for analysis of time trends. Continuous data with normal distribution were compared with the Student's $t$ test; those without normal distribution were compared with the Mann-Whitney $U$ test. Survival was analyzed by the Kaplan-Meier method, ${ }^{7}$ and evaluation of the difference was conducted by log-rank test. ${ }^{8}$ Multivariance analysis of the prognostic factors was conducted by Cox's regression model. ${ }^{9}$ Differences with $p$ values not greater than 0.05 were regarded as statistically significant. All the above-mentioned statistical analysis was performed with SPSS for Windows software system (SPSS Inc, Chicago, Ill.).

\section{Results}

Distribution of patients. There were no significant sex differences among the three groups. The mean ages at the early, middle, and late periods were $59.7,61.2$, and 63.0 years, respectively, with significant increases at the later periods. With respect to the histologic type, the ratio of patients with adenocarcinoma showed significant increase at the middle and late periods (Table I).
With regard to staging (Table II), the ratio of stage I disease increased significantly at the middle and the late periods, mainly as a result of an increase in the ratio of pT1 NO MO disease at the late period $(8.7 \%$ at the early period, $17.9 \%$ at the middle period, $25.4 \%$ at the late period). The ratio of patients with p-stage II disease in all the study periods was about $10 \%$. The ratio of patients with p-stage IIIa disease showed significant decrease in the late period, mainly as a result of decrease in the ratio of patients with pT3 N2 M0 disease $(13.0 \%$ at the early period, $6.1 \%$ at the middle period, $2.6 \%$ at the late period). There were no significant changes in the ratio of patients with p-stage IIIb or p-stage IV disease.

Exploratory thoracotomy, complete resection, and operation-related death. The rate of exploratory thoracotomy significantly decreased at the late period $(9.1 \%$ at the early period, $4.8 \%$ at the middle period, $2.9 \%$ at the late period; Table III). Complete tumor resection with lymph node dissection was performed in 120, 198, and 258 patients at the early, middle, and late periods, respectively, complete tumor resection without lymph node dissection was performed in six, three, and 13 patients, respectively. The rate of complete tumor resection with lymph node dissection showed significant increase at the later periods. The rates of operation-related death at the early, middle, and late periods were $3.8 \%, 3.4 \%$, and $0.9 \%$, respectively, showing significant decrease at the later period.

Survival after operation. The 5-year survival increased significantly, from $31.5 \%$ at the early period to $39.0 \%$ at the middle period and $54.0 \%$ at the late 
Table II. Pathologic staging of disease

\begin{tabular}{|c|c|c|c|c|c|c|c|}
\hline & \multicolumn{6}{|c|}{ Year of operation } & \multirow[b]{3}{*}{ Time trend $P$} \\
\hline & \multicolumn{2}{|c|}{$\begin{array}{c}1976 \text { to } 1980 \\
(n=208)\end{array}$} & \multicolumn{2}{|c|}{$\begin{array}{c}1981 \text { to } 1985 \\
(n=291)\end{array}$} & \multicolumn{2}{|c|}{$\begin{array}{c}1986 \text { to } 1990 \\
(n=346)\end{array}$} & \\
\hline & No. & $\%$ & No. & $\%$ & No. & $\%$ & \\
\hline Stage I $(n=289)$ & 43 & 20.7 & 93 & $32.0^{*}$ & 153 & $44.2 \dagger \ddagger$ & $<0.01$ \\
\hline T1 N0 M0 $(n=158)$ & 18 & 8.7 & 52 & $17.9^{*}$ & 88 & $25.4 \uparrow$ & $<0.01$ \\
\hline T2 No M0 $(n=131)$ & 25 & 12.0 & 41 & 14.1 & 65 & 18.8 & 0.03 \\
\hline Stage II $(n=72)$ & 22 & 10.6 & 24 & 8.2 & 26 & 7.5 & 0.23 \\
\hline T1 N1 M0 $(n=25)$ & 8 & 3.8 & 7 & 2.4 & 10 & 2.9 & 0.59 \\
\hline T2 N1 M0 $(n=47)$ & 14 & 6.7 & 17 & 5.8 & 16 & 4.6 & 0.28 \\
\hline Stage IIIa $(n=287)$ & 90 & 43.3 & 110 & 37.8 & 87 & $25.1 \uparrow \S$ & $<0.01$ \\
\hline T3 N0-1 M0 $(n=116)$ & 39 & 18.8 & 46 & $15.8 \|$ & 31 & $9.0 \dagger$ & $<0.01$ \\
\hline T1-2 N2 M0 $(n=118)$ & 24 & 11.5 & 46 & 15.8 & 48 & 13.9 & 0.59 \\
\hline T3 N2 M0 $(n=53)$ & 27 & 13.0 & 18 & $6.2 \|$ & 8 & $2.3+\S$ & $<0.01$ \\
\hline Stage IIIb $(n=100)$ & 27 & 13.0 & 33 & 11.3 & 40 & 11.6 & 0.65 \\
\hline T4 N0-1 M0 $(n=37)$ & 10 & 4.8 & 11 & 3.8 & 16 & 4.6 & 0.99 \\
\hline T4 N2 M0 $(n=43)$ & 15 & 7.2 & 15 & 5.2 & 13 & 3.8 & 0.08 \\
\hline Any T N3 M0 $(n=20)$ & 2 & 1.0 & 7 & 2.4 & 11 & 3.2 & 0.10 \\
\hline Stage IV $(n=97)$ & 26 & 12.5 & 31 & 10.7 & 40 & 11.6 & 0.80 \\
\hline
\end{tabular}

Time trend analysis by $\chi^{2}$ test. $^{6}$

${ }^{*} p<0.01,1976$ to 1980 vs 1981 to 1985.

$\dagger p<0.01,1976$ to 1980 vs 1986 to 1990 .

$\ddagger p<0.05,1981$ to 1985 vs 1986 to 1990 .

$\S p<0.01,1981$ to 1985 vs 1986 to 1990 .

$\| p<0.05,1976$ to 1980 vs 1981 to 1985 .

Table III. Rates of exploratory thoracotomy, complete resection with lymph node dissection, and operation-related death

\begin{tabular}{|c|c|c|c|c|c|c|c|}
\hline & \multicolumn{6}{|c|}{ Year of operation } & \multirow[b]{3}{*}{ Time trend $P$} \\
\hline & \multicolumn{2}{|c|}{$\begin{array}{c}1976 \text { to } 1980 \\
(n=208)\end{array}$} & \multicolumn{2}{|c|}{$\begin{array}{c}1981 \text { to } 1985 \\
(n=291)\end{array}$} & \multicolumn{2}{|c|}{$\begin{array}{c}1986 \text { to } 1990 \\
(n=346)\end{array}$} & \\
\hline & $\%$ & No. & $\%$ & No. & $\%$ & No. & \\
\hline Exploratory thoracotomy & 9.1 & $19 / 208$ & 4.8 & $14 / 291$ & 2.9 & $10 / 346^{*}$ & $<0.01$ \\
\hline $\begin{array}{l}\text { Complete tumor resec- } \\
\text { tion with lymph node } \\
\text { dissection }\end{array}$ & 57.7 & $120 / 208$ & 68.0 & $198 / 291 \dagger$ & 74.6 & $258 / 346^{*}$ & $<0.01$ \\
\hline Operation-related death & 3.8 & $8 / 208$ & 3.4 & $10 / 291$ & 0.9 & $3 / 346 \neq \S$ & 0.02 \\
\hline
\end{tabular}

Time trend analysis by $\chi^{2}$ test. $^{6}$

${ }^{*} p<0.01,1976$ to 1980 vs 1986 to 1990 .

$\pitchfork p<0.05,1976$ to 1980 vs 1981 to 1985.

$\dot{t} p<0.05,1976$ to 1980 vs 1986 to 1990 .

$\S p<0.05,1981$ to 1985 vs 1986 to 1990 .

period, with prominent improvement at the late period ( $p<0.01$ for the early or middle period versus the late period; Fig. 1, Table IV). The 5-year survivals of patients with p-stage I at all the study periods were around $70 \%$, showing no significant difference. The 5-year survival rate of patients with p-stage II disease at the late period was $74.8 \%$, showing significant improvement of prognoses compared with those at the early and middle periods
( $p<0.05$ and $p<0.01$, respectively). The 5-year survival of patients with p-stage IIIa disease at the late period was $49.5 \%$, showing significant improvement compared with those at the early and middle periods $(p<0.01$ for both); the 5-year survivals of patients with $p$-stage IIIa $\mathrm{pN} 2$ disease showed marked improvement at the late period, whereas those of patients with p-stage IIIa pT3 (N0 or 1) disease showed no significant improvement. Among 


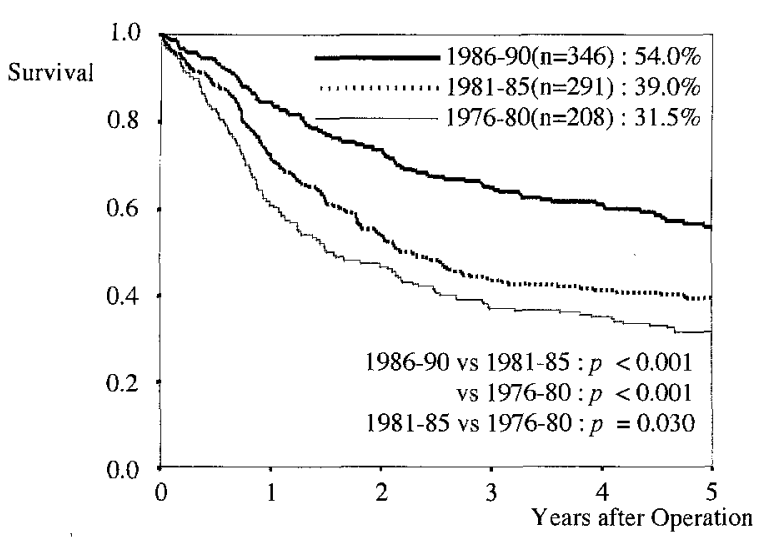

Fig. 1. Survival curves of all patients for the three study periods, 1986 through 1990, 1981 through 1985, and 1976 through 1990.

patients with p-stage IIIa pN2 disease, there were no significant differences among the three study groups with respect to patients, histologic characteristics, preoperative mediastinal lymph node evaluation, and distribution of involved mediastinal lymph nodes, except for significant decrease in the number of patients with pT3 N2 M0 disease with poor prognosis (Fig. 2). The 5-year survivals of patients with p-stage IIIb pT4 (N0 or 1) disease at the middle and late periods showed significant improvement compared with those at the early period, whereas those of patients with p-stage $\mathrm{IIIb}, \mathrm{pN} 3$ or p-stage IV disease were $0 \%$ at all the study periods.

Results of the analysis of the cases of 576 patients who underwent complete tumor resection with lymph node dissection were almost the same as those for all 845 patients. There was no significant improvement in the postoperative prognosis of p-stage I and p-stage IIIb diseases, whereas significant improvement in prognosis was observed for p-stage II disease and p-stage IIIa pN2 disease (Table V).

Multivariate analysis of the prognostic factors. Results of the multivariative analysis of the prognostic factors with Cox's regression mode are shown in Table VI. Factors with strong influence on the postoperative survival were mode of operation (whether complete tumor resection with lymph node dissection was achieved, $p<0.001$ ) and status of pathologic lymph node involvement $(p<$ $0.001)$. Older age proved to be another strong factor in poor prognosis $(p<0.001)$, as did male $\operatorname{sex}(p=0.011)$.

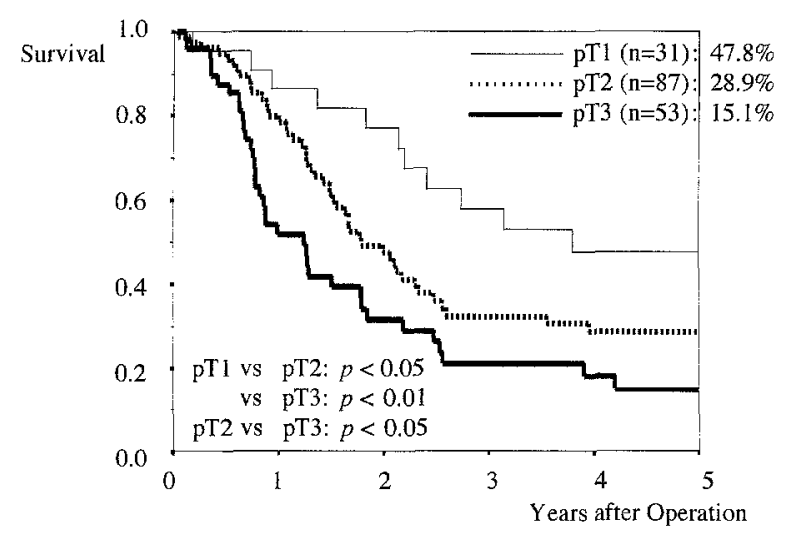

Fig. 2. Survival curves of $\mathrm{pN} 2$ patients for the three disease states, pT1, pT2, and pT3.

\section{Discussion}

There have been many reports dealing with survival after operation for PLC defined according to the current TNM classification. In two reports that were based on more than 1000 cases, ${ }^{3,10} 5$-year survivals were $57.0 \%$ to $75.5 \%$ among patients with p-stage I (pT1 or pT2 N0 M0) disease, $38.4 \%$ to $54.1 \%$ among patients with p-stage II (pT1 or pT2 N1 M0) disease, $15.1 \%$ to $44.2 \%$ in patients with p-stage IIIa (pT3 or pN2 M0), and $0.0 \%$ to $8.2 \%$ among patients with p-stage IIIb (pT4 or pN3 M0) disease. There have been only a few reports, however, stratifying survival after operation by year of operation. Jie and coworkers ${ }^{2}$ reported that there was no improvement in survival after operation for 920 patients with non-small-cell lung cancer during the period from 1969 to 1985 . In their report, however, patients with squamous cell carcinoma comprised $67.7 \%$ of the sample (623 patients), which seemed to be a greater rate than in other reports. ${ }^{9}$ Moreover, the 5-year survival of patients with p-stage I disease was only $47.0 \%$, which seems low compared with those in other reports. ${ }^{3,10}$ Data reported by Jie and coworkers ${ }^{2}$ are not considered to represent exactly the present status of surgery for PLC. In our time trend analysis regarding survival after operation during the past 15 years (from 1976 to 1990) according to the current TNM classification, ${ }^{3}$ we found significant improvement from the early period (1976 to 1980 ) to the middle (1981 to 1985 ) and the later (1986 to 1990) periods.

We analyzed factors contributing to improvement of postoperative survival, one of which may be 
Table IV. Five-year survivals of patients who underwent thoracotomy for PLC cancer during 1976 to 1980, 1981 to 1985 , and 1986 to 1990

\begin{tabular}{|c|c|c|c|c|c|c|}
\hline & \multicolumn{6}{|c|}{ Year of operation } \\
\hline & \multicolumn{2}{|c|}{$\begin{array}{c}1976 \text { to } 1980 \\
(n=208)\end{array}$} & \multicolumn{2}{|c|}{$\begin{array}{c}1981 \text { to } 1985 \\
(n=291)\end{array}$} & \multicolumn{2}{|c|}{$\begin{array}{c}1986 \text { to } 1990 \\
(n=346)\end{array}$} \\
\hline & $\%$ & No. & $\%$ & No. & $\%$ & No. \\
\hline Stage I $(n=289)$ & 68.2 & 43 & 72.6 & 93 & 75.1 & 153 \\
\hline Stage II $(n=72)$ & 45.5 & 22 & 38.6 & 24 & 74.8 & $26^{*} \dagger$ \\
\hline Stage IIIa $(n=287)$ & 21.7 & 90 & 29.6 & 110 & 49.5 & $87 \dagger+$ \\
\hline T3 N0-1 M0 $(n=116)$ & 33.5 & 39 & 42.7 & 46 & 62.5 & 31 \\
\hline Any T N2 M0 $(n=171)$ & 11.8 & 51 & 19.4 & 64 & 41.4 & $56+t$ \\
\hline Stage IIIb $(n=100)$ & 11.7 & 27 & 15.2 & 33 & 23.1 & $40^{*}$ \\
\hline T4 N0-1 M0 $(n=37)$ & 10.0 & 10 & 36.4 & $11 \S$ & 43.3 & $16^{*}$ \\
\hline Any T N3 M0 $(n=20)$ & 0.0 & 2 & 0.0 & 7 & 0.0 & 11 \\
\hline Stage IV $(n=97)$ & 6.2 & 26 & 0.0 & 31 & 0.0 & 40 \\
\hline $\begin{array}{l}0.05,1976 \text { to } 1980 \text { vs } 1986 \text { to } 1990 \\
0.01,1981 \text { to } 1985 \text { vs } 1986 \text { to } 1990 \\
0.01,1976 \text { to } 1980 \text { vs } 1986 \text { to } 1990 \\
0.05,1976 \text { to } 1980 \text { vs } 1981 \text { to } 1985\end{array}$ & & & & & & \\
\hline
\end{tabular}

improvement of surgical technique. There were no differences in sex distribution among the study periods. Older age observed at the later periods was a prognostic factor for a poor prognosis rather than a good one, as shown by the multivariate analysis $(p<$ 0.01 ). The ratio of patients with adenocarcinoma increased at the middle and the late periods; the histologic type (whether adenocarcinoma or another type), however, did not prove to be a dependent prognostic factor, as shown by the multivariate analysis.

Analysis of the stage stratified by year of operation showed an increase in the ratio of patients with stage I disease, which was a factor in improvement in the prognosis of all candidates for operation. Increase in the number of patients with pT1 N0 M0 disease was particularly marked, which suggests increase in the early detection of a lung tumor as a result of improvement of the diagnostic technique (thoracic imaging and fiberoptic bronchoscopy) and increase in mass examination. Decrease in the number of patients with p-stage IIIa disease, which was mainly a result of the decrease in the number of patients with pT3 N2 M0 disease and poor prognosis, also contributed to overall improvement in prognosis. The decrease in patients with pT3 N2 M0 disease suggests that preoperative evaluations of the local tumor extension and of the status of mediastinal nodes involvement have become more accurate with introduction of chest CT in 1981, progress in speed and resolution of CT, and increased diagnostic ability of the radiologists, which has allowed the exact diagnosis of inoperable disease. This surmise is supported by the significant decrease in patients who underwent exploratory thoracotomy and by the significant increase in patients who underwent complete tumor resection. As shown by the multivariate analysis, whether complete tumor resection could be achieved is an extremely strong prognostic factor $(p<0.001)$, and exact preoperative diagnosis of inoperable cases is therefore considered an important factor in better prognosis.

The prognoses of patients with the same stage disease among the study periods were compared. The 5-year survivals of patients with p-stage I disease were about $70 \%$ in all study periods, which agreed with survivals reported by other investigators. $^{3,13}$ The 5 -year survivals of patients with p-stage II at the early and middle periods were $45.5 \%$ and $38.6 \%$, respectively, which were almost the same as those reported by other investigators (about $35 \%$ to $50 \%)^{3,}, 10,14,15$ On the other hand, the survival at the late period was extremely high $(74.8 \%)$; the reason for this could not be clarified because of the small number of cases. Because the number of patients with p-stage II disease in a single medical institution is quite limited, it is necessary to conduct a large-scale multiinstitutional study for the exact evaluation of the survival after operation and adjuvant therapy for p-stage II disease. ${ }^{14}$ With respect to p-stage IIIa disease, pT3 (N0-1) disease and pN2 disease should be analyzed separately. The 5-year survivals of patients with pT3 disease without mediastinal lymph node metastasis showed a tendency 
Table V. Five-year survivals of patients who underwent complete tumor resection with lymph node dissection

\begin{tabular}{|c|c|c|c|c|c|c|}
\hline & \multicolumn{6}{|c|}{ Year of operation } \\
\hline & \multicolumn{2}{|c|}{$\begin{array}{c}1976 \text { to } 1980 \\
(n=120)\end{array}$} & \multicolumn{2}{|c|}{$\begin{array}{c}1981 \text { to } 1985 \\
(n=198)\end{array}$} & \multicolumn{2}{|c|}{$\begin{array}{c}1986 \text { to } 1990 \\
(n=258)\end{array}$} \\
\hline & $\%$ & No. & $\%$ & No. & $\%$ & No. \\
\hline Stage I $(n=276)$ & 73.1 & 43 & 73.7 & 90 & 72.2 & 145 \\
\hline Stage II $(n=68)$ & 52.6 & 20 & 40.6 & 22 & 84.9 & $26^{*}+$ \\
\hline Stage IIIa $(n=206)$ & 34.3 & 53 & 36.4 & 82 & 54.5 & $71 *+$ \\
\hline T3 N0-1 M0 $(n=87)$ & 48.0 & 26 & 49.5 & 36 & 70.9 & 25 \\
\hline Any T N2 M0 $(n=119)$ & 20.4 & 27 & 27.2 & 46 & 44.9 & $46 \div 8$ \\
\hline Stage IIIb $(n=17)$ & 0.0 & 4 & 0.0 & 4 & 11.2 & 16 \\
\hline
\end{tabular}

${ }^{*} p<0.05,1976$ to 1980 vs 1986 to 1990 .

$\dagger p<0.01,1981$ to 1985 vs 1986 to 1990.

p $<0.05,1981$ to 1985 vs 1986 to 1990 .

$\S p<0.01,1976$ to 1980 vs 1986 to 1990 .

Table VI. Multivariate analysis of prognostic factors

\begin{tabular}{llrrr}
\hline Prognostic factor & \multicolumn{1}{c}{ Difference measured } & \multicolumn{1}{c}{$p$} & $R R$ & $95 \%$ CI \\
\hline Sex & Male/female & 0.01 & 0.67 & $0.51-0.87$ \\
Age & 10 yr interval & $<0.01$ & 1.28 & $1.13-1.43$ \\
Histologic type & Nonadenocarcinoma, adenocarcinoma & 0.72 & 0.98 & $0.78-1.23$ \\
Operation & Complete tumor resection and lymph & $<0.01$ & 0.43 & $0.33-0.57$ \\
T & $\quad$ node dissection (not done, done) & & & \\
N & $1,2,3,4$ & 0.01 & 1.24 & $1.09-1.41$ \\
Year of operation & $0,1,2,3$ & $<0.01$ & 1.71 & $1.53-1.92$ \\
\hline
\end{tabular}

$R R$, Relative risk; $\mathrm{Cl}$, confidence interval.

toward improvement at the late period, although this was not statistically significant. The values were consistent with those reported by other investigators (33.3\% to $53.7 \%$ for patients with pT3 N0 M0 disease, $17.6 \%$ to $39.0 \%$ for patients with pT3 N1 M0 disease. ${ }^{3,10,16}$ The 5-year survival rates of patients with $\mathrm{pN} 2$ disease at the early and middle periods were $11.8 \%$ and $19.4 \%$, respectively, which were almost the same as those reported by other investigators $\left(28.8 \%,{ }^{3} \quad 15.1 \%,{ }^{10}\right.$ and $\left.20.1 \%{ }^{17}\right)$, whereas that at the late period was extremely high $(43.3 \%)$. The improvement in the prognosis of patients with $\mathrm{pN} 2$ disease at the later periods was caused by the decrease in the patients with pT3 N2 M0 disease, which suggests that operation without effective induction therapy is not justified in patients with T3 N2 M0 disease. The 5-year survivals of patients with p-stage IIIb and IV disease were almost $0 \%$, except for patients with p-stage IIIb pT4 N0-1 disease during the entire study periods. Operation should therefore be considered only when preoperative evaluations indicate that complete re- section can be achieved for $\mathrm{T} 4$ disease without mediastinal involvement.

As clearly demonstrated by the multivariate analysis of the prognostic factors, control of lymph node metastasis is a key to improvement in prognosis. Analysis of the postoperative survivals stratified by stage showed significant improvement at the late period among patients with lymph node metastasis; that is, p-stage II pN1 disease or p-stage IIIa pN2 disease. What are the main factors of improvement in prognosis? Operation alone evidently cannot achieve a good prognosis in $\mathrm{pN} 2$ disease; Rosell and coworkers $^{18}$ reported that the 5-year survival of patients who underwent operation for p-stage IIIa non-small-cell lung cancer, most with pN2 disease, was $0 \%$. We could not determine a definite reason for our results being better except for the decrease in patients with pT3 N2 M0 disease, which contributed to the improvement of overall postoperative prognosis in patients with $\mathrm{pN} 2$ disease. Because various postoperative adjuvant chemotherapy and radiotherapy were employed for patients with $\mathrm{pN} 1$ 
and N2 disease, the efficacy of the postoperative adjuvant therapy should be analyzed in further study.

We thank Nobuyuki Hamajima, MD, MPH, Division of Epidemiology, Aichi Cancer Research Institute, Aichi, Japan, for helpful comment and critical reading of the statistical section of the manuscript.

\section{REFERENCES}

1. Shields TW. Surgical treatment of non-small cell bronchial carcinoma. In: Shields TW, editor. General thoracic surgery. 4th ed. Philadelphia: Williams \& Wilkins, 1994:1169-77.

2. Jie C, Wever AM, Huysmans HA, Franken HC, Wever-Hess $\mathrm{J}$, Hermans $\mathrm{J}$. Time trends and survival in patients presented for surgery with non-small-cell lung cancer 1969-1985. Eur J Cardiothorac Surg 1990;4:653-7.

3. Mountain CF. A new international staging system for lung cancer. Chest 1986;89 (Suppl):225S-33S.

4. Strauss GM, Langer MP, Elias AD, Skarin AT, Sugarbaker DJ. Multimodality treatment of stage IIIA non-small-cell lung carcinoma: a critical review of the literature and strategies for future research. J Clin Oncol 1992;10:829-38.

5. World Health Organization. The World Health Organization: histological typing of lung tumors. 2nd edition. Am J Clin Pathol 1982;77:123-36.

6. Altman DG. Chi-square test for trend. In: Altman DG, ed. Practical statistics for medical research. London: Chapman \& Hill, 1991:261-5.

7. Kaplan EL, Meier P. Nonparametric estimation from incomplete observations. J Am Statist Assoc 1958;53:457-81.

8. Kalbfleisch JD, Prentice RL. The statistical analysis of failure time data. New York: John Wiley, 1980:16-9.

9. Cox DR. Regression models and life tables. J R Stat Soc 1972;34:187-220.
10. Naruke T, Goya T, Tsuchiya R, Suemasu K. Prognosis and survival in resected lung carcinoma based on the new international staging system. J Thorac Cardiovasc Surg 1988;96: 440-7.

11. Immerman SC, Vanecko RM, Fry WA, Head LR, Shields TW. Sites of recurrence in patients with stages I and II carcinoma of the lung cancer. Ann Thorac Surg 1981;32: $23-7$.

12. Martini N, Beattie EJ Jr. Results of surgical treatment in stage I lung cancer. J Thorac Cardiovasc Surg 1977;74:499505.

13. Williams DE, Pairolero PC, Davis CS, Bernatz PE, Payne WS, Taylor WF, et al. Survival of patients surgically treated for stage I lung cancer. J Thorac Cardiovasc Surg 1981;82: 70-6.

14. Martini N, Burt ME, Bains MS, McCormack PM, Rusch VW, Gingeberg RJ. Survival after resection of stage II non-small cell lung cancer. Ann Thorac Surg 1992;54:460-6.

15. Yano $T$, Yokoyama $H$, Inoue $T$, Asoh $H$, Tayama $K$, Ichinose $Y$. Surgical results and prognostic factors of pathologic N1 disease in non-small-cell carcinoma of the lung. $\mathbf{J}$ Thorac Cardiovasc Surg 1994;107:1398-402.

16. Piehler JM, Pairolero PC, Weiland LH, Offord KP, Payne WS, Bernatz PE. Bronchogenic carcinoma with chest wall invasion: factors affecting survival following en block resection. Ann Thorac Sụrg 1982;34:684-91.

17. Goldstraw P, Mannam GC, Kaplan DK, Michail P. Surgical management of non-small-cell lung cancer with ipsilateral mediastinal node metastasis (N2 disease). J Thorac Cardiovasc Surg 1994;107:19-28.

18. Rosell R, Gómez-Condina J, Camps C, Maestre J, Padille J, Cantó A, et al. A randomized trial comparing preoperative chemotherapy plus surgery with surgery alone in patients with non-small-cell lung cancer. N Engl J Med 1994;330: 153-8. 